\title{
O Ensino Sociológico nos Estabelecimentos de Ensino Médio: entre problemas sociais e sociologia acadêmica
}

\author{
Elisabeth Chatel' \\ Gérard Grosse" \\ 'Université de Rouen, Rouen - França \\ "Lycée Racine, Paris - França
}

RESUMO - O Ensino Sociológico nos Estabelecimentos de Ensino Médio: entre problemas sociais e sociologia acadêmica. Desde a sua criação em 1966, em uma disciplina escolar, o ensino de sociologia para estudantes franceses do Ensino Médio tem como objetivo o desenvolvimento de uma atitude reflexiva e uma perspectiva crítica sobre o mundo social. Uma pesquisa realizada entre os alunos de segundo ano mostra em que medida esse objetivo é parcialmente alcançado. Os sistemas didáticos implementados são analisados em sua tensão entre dois modelos. Um deles, o uso da análise social, prevaleceu até os anos 1980, o outro, o que tende a se desenvolver, tem uma maior aproximação com uma introdução à sociologia.

Palavras-chave: Disciplina Escolar. Currículo Real. Ensino de Sociologia. Ferramentas Didáticas. Currículo Formal.

ABSTRACT - The Sociological Teaching in High Schools: between social problems and academic sociology. Since its creation in 1966, in a school discipline, teaching sociology for high school French students of aims to develop a reflective attitude and a critical perspective on the social world. A survey conducted among the students of the second year, shows the extent to which this goal is partially achieved. The didactic systems implemented are analyzed in their tension between two models. One, the use of social analysis prevailed until the 1980s, the other, which tends to develop, have a closer relationship with an introduction to sociology.

Keywords: School Discipline. Real Curriculum. Teaching Sociology. Teaching Tools. Formal Curriculum. 
O ensino da sociologia nos estabelecimentos de Ensino Médio na França recentemente encontrou um lugar dentro de uma disciplina escolar, as ciências econômicas e sociais. Esta foi criada em 1966 e só existe na opção de formação econômica e social (ES) ${ }^{1}$ das escolas de Ensino Médio. Não cabe aqui traçar a história tumultuosa da inclusão desta disciplina na educação francesa (Chatel; Grosse; Richet, 2002), mas apenas enfatizar que, estando limitados a essa opção de formação, só $29 \%$ dos alunos de formação geral e tecnológica têm acesso a ela, ou seja, 20\% de todos os alunos do Ensino Médio em 2002. Questionar o papel da sociologia no currículo desses alunos remete de uma forma particular à questão da circulação do conhecimento.

Para abordar especificamente o ensino das ciências do homem e da sociedade e destacar as mudanças significativas que a intenção de ensinar provoca sobre o conhecimento do homem, Michel Verret (1974) cria a expressão transposição didática. Posteriormente, o termo foi usado para analisar a questão da legitimidade do conhecimento ensinado. Mas nós queremos identificar o conteúdo do currículo real da sociologia nas escolas de Ensino Médio. O conceito de transposição, tomado em um sentido mais amplo, é uma forma de destacar as transformações pelas quais passam os conhecimentos quando eles circulam da esfera acadêmica ou prática para o ensino em si próprio. Esse será o fio condutor de nossa discussão, levando-nos, além do exame do papel da sociologia no currículo de ciências econômicas e sociais (CES) ${ }^{2}$, para evocar os ecos que se enviam mutuamente às esferas acadêmicas, midiáticas e políticas, assim como seus efeitos no universo escolar e, consequentemente, sobre a didatização dos conhecimentos. É a partir dos resultados dos alunos que examinaremos o papel da sociologia nas escolas francesas no primeiro, no segundo e no terceiro ano do Ensino Médio. Em seguida, abordaremos o dispositivo curricular que permitiu essas aprendizagens, o qual se embasa entre dois modelos didáticos, e finalmente questionaremos a sua evolução.

\section{Recepção da Sociologia pelos Estudantes do Ensino Médio}

Embora o discurso sobre a avaliação tenha se desenvolvido muito nos últimos 20 anos, há poucos elementos que permitem ter uma ideia sobre a recepção de um ensino específico por esses estudantes. No que diz respeito às ciências econômicas e sociais, no entanto, não há dúvidas de que os alunos têm interesse nesta matéria. Muitas vezes, eles se mobilizaram para defendê-la e, mais recentemente, suas respostas à consulta sobre as escolas, organizadas sob a égide de Philippe Meirieu em 1998, indicam uma recepção positiva inabalável (Hameline, 1998). A dimensão sociológica que ela comporta parece ser um ponto forte.

Em 1998-1999, realizamos uma pesquisa com 700 alunos do segundo ano da ES, acompanhando um teste para avaliar seus conhecimentos sobre o tema da socialização (Chatel et al., 2003). Realizado du- 
rante o segundo ano, entre duas semanas e dois meses após a conclusão do curso sobre a socialização, a pesquisa incluiu um questionário (explicado pelo professor da turma e preenchido por cada aluno) e um teste constituído por quatro exercícios. Os três primeiros, realizados com o acesso ao material de apoio, consistiam de exercícios nos quais precisavam dar um conteúdo preciso, colocando-se ficticiamente na posição de um professor que está preparando um dispositivo de estudo. Para cada um, era necessária a redação de uma correção. O quarto exercício pedia para escrever pelo menos 50 linhas, sem consulta ao material de apoio, para explicar a um colega o que significa a socialização. As provas preenchidas foram exploradas de duas maneiras: primeiro estatisticamente, após a conversão de respostas abertas dos alunos em perguntas fechadas utilizadas como uma pesquisa, e em seguida retornando qualitativamente aos textos originais dos alunos.

Essa avaliação incluiu algumas perguntas para avaliar o seu ensino. As respostas confirmam o interesse na dimensão sociológica, o qual é mais significativo entre as meninas. Para os alunos que se expressam, a entrada na reflexão sociológica é muitas vezes pensada em termos de tomada de consciência, de oportunidade de fornecer explicações aos fenômenos que os dizem respeito, porque eles falam deles. No entanto o interesse dos alunos nesses aspectos sociológicos não é cego, eles são mais sensíveis a certos temas (a família, as diferenças culturais, a diferenciação sexual, a mobilidade social), enquanto outros aspectos lhes parecem difíceis e muito abstratos. Sua capacidade de relatar dificuldades mostra o quanto suas respostas são frutos de reflexão.

Mas o interesse por questões sociológicas não garante que esses alunos penetraram na sociologia como universo de significações, modo de raciocínio ou método de trabalho. Nossa avaliação procurou testar o acesso ao conhecimento sociológico, sem, contudo, padronizar um questionário a priori. Começamos com os programas e os exercícios habituais desse ensino escolar. Os programas oficiais definem escolhas entre uma variedade de conteúdos de conhecimentos a serem ensinados e os põem em uma ordem, eles especificam e limitam o significado, listam os conceitos considerados essenciais em cada tema. Desde 1988, os programas são apresentados em colunas, o que, em particular para os textos de 1992 a 1995, permite expor o conteúdo na primeira coluna, especificar em uma segunda coluna conceitos e noções cuja assimilação pelos alunos é esperada, em relação a cada item do programa, e para o terceiro ano, em uma terceira coluna, delimitar a interpretação individual por meio de um comentário. O conjunto é precedido de uma apresentação geral, lembrando os objetivos e os propósitos do ensino e explicando as principais escolhas realizadas.

Entre os exercícios habituais do ensino escolar, o trabalho com documentos, notadamente estatísticos, constitui a marca específica das ciências sociais e econômicas. Saber lê-los precisamente para responder às perguntas, saber mobilizar sinteticamente os dados de vários

Educação \& Realidade, Porto Alegre, v. 39, n. 1, p. 99-111, jan./mar. 2014.

Disponível em: <http://www.ufrgs.br/edu_realidade> 
documentos para sustentar uma argumentação formam o cotidiano do trabalho escolar em sala de aula de CES. A maioria dos alunos se mostrou capaz de entrar no jogo, ou seja, momentaneamente adotar a posição de professor que faz os exercícios para o estudo de um tema. Ao fazer isso, eles mostraram que dominavam esses exercícios e davam suficientemente significado ao tema.

Em seus escritos domina um sentido bastante determinista da socialização: é a necessidade de os indivíduos se submeterem ao molde social, condição imperativa e vista como bastante dolorosa, para ser integrada. Os principais conceitos escolhidos são adequados ao programa: os agentes, as instâncias e o processo de socialização. De acordo com o programa, os estudantes colocam ênfase na socialização primária e na reprodução da sociedade. Mas também se encontra muitas vezes uma tradução um pouco redutora. Assim, o conceito de aprendizagem pode se tornar uma simples repetição, ou o hábito leva a fazer da reprodução um determinismo sem nuance. Seu nível de domínio do conhecimento relacionado com a socialização é variável.

De modo geral, os alunos têm acesso ao uso adequado do vocabulário dos conceitos incluídos no programa. No texto normativo de 1994, por exemplo, norma, personalidade social, status, papel, valor, socialização, inato e adquirido são noções indexadas no tema socialização. Dos testes, $37,5 \%$ conseguem associar em todos os casos, de modo aceitável para nós, uma palavra do vocabulário sociológico considerada importante a uma situação para ilustrá-la. Apenas em oito provas $(1,1 \%)$ não foi identificada nenhuma associação. Em uma análise de correspondência múltipla, esse exercício, testando o domínio do vocabulário de base, se mostrou não discriminante.

A exploração quantitativa e qualitativa dessa pesquisa nos permite elaborar um quadro sintético dos tipos de aprendizagem dos estudantes sobre esse assunto, ao final do segundo ano, que nós consideramos básico.

Um primeiro grupo de alunos, pouco numeroso, permanece de certa forma fora do jogo: os testes não estão concluídos, são realizados de forma fantasista. Um segundo grupo, mais numeroso, mostra estudantes capazes de utilizar judiciosamente o vocabulário definido no programa. Quando questionados sobre o que é a socialização, eles retomam os termos da aula de forma bastante fiel e, portanto, mais ou menos exatos. Mas o curso é recitado sem que apareçam sinais de apropriação pessoal. Apesar da utilização de um novo léxico, nada garante que eles tenham entrado num questionamento sociológico. Em vez disso, ao que parece na análise mais qualitativa das suas produções, essas novas palavras muitas vezes vestem estereótipos que permanecem inalterados. Um terceiro grupo de estudantes emerge, podendo-se dizer que este iniciou uma reflexão sobre os fenômenos da sociedade. Para achar um caminho, os seus pensamentos empregam, em diversos graus, e mais ou menos habilmente, o vocabulário da sociologia. Ape-

102 Educação \& Realidade, Porto Alegre, v. 39, n. 1, p. 99-111, jan./mar. 2014 Disponível em: <http://www.ufrgs.br/edu_realidade> 
sar de as reflexões permanecerem embrionárias e, por vezes, a escrita ficar ainda hesitante, os traços de um verdadeiro questionamento são óbvios, a capacidade desses alunos, seja para analisar detalhadamente um texto, seja para interpretar de forma reflexiva um fenômeno do mundo social, testemunha nesse sentido. Este grupo tem um número relativamente grande de estudantes. Mais de um terço dos alunos escreveram um texto sobre a socialização, defendendo uma tese argumentada sobre o assunto e a sustentaram com exemplos; $9 \%$ dos textos apresentam um entendimento da aula que julgamos aprofundada; e $22 \%$ expressam uma reflexão pessoal sobre o assunto. Para estes alunos, um pequeno passo foi dado, fazendo-os entrar, ou pelo menos entrever, um novo mundo de reflexão.

Embora pequeno, esse resultado é importante porque supõe muito mais do que aprender pela familiarização ou pela repetição. Primeiro, ele exige que os alunos utilizem adequadamente um novo léxico. Além da restituição oportuna de um discurso, eles estão obrigados a produzir um texto que não está escrito com antecedência. Portanto eles precisam mobilizar tanto o que foi aprendido quanto a sua própria interpretação dos fenômenos do mundo que eles terão construído como fenômenos sociais.

Sem tentar fazer uma generalização, um exemplo permite compreender os resultados dos alunos no final do terceiro ano. O estudo de uma prova de uma muito boa aluna do terceiro ano de ES (ano letivo 2000-2001) mostra que o assunto Até que ponto as mudanças nas estruturas econômicas e sociais durante os últimos 30 anos levam a uma redução dos conflitos? foi compreendido e a tarefa foi bem construída. A aluna menciona de maneira pertinente autores não citados no material de apoio, acompanhando o assunto (Marx, Tocqueville, Touraine, Olson). Há também referências, devidamente colocadas, aos conceitos de classe trabalhadora, classe média, mobilidade social, movimentos sociais, consciência de classe, desestabilização da condição salarial. Em suma, esta tarefa, que não tem nada de excepcional, mostra que no final do ensino secundário muitos alunos são capazes de encaixar a sua reflexão no molde de uma problemática sociológica, de mobilizar conceitos e referências aos autores, de produzir uma argumentação sustentada por uma utilização racional de dados numéricos.

\section{Aprender e Refletir os Fenômenos Sociais: dois modelos de ensino}

Levar os alunos rumo a esse caminho é, no fundo, o objetivo que foi definido desde a criação da formação econômica e social para o Ensino Médio. A formulação varia um pouco, mas não a finalidade. Em 1966, quando esse ensino é criado, ele absorve na formação em que está presente o tempo dedicado à educação cívica, endossando e ampliando a sua missão. As instruções iniciais declaram que a educação

Educação \& Realidade, Porto Alegre, v. 39, n. 1, p. 99-111, jan./mar. 2014.

Disponível em: <http://www.ufrgs.br/edu_realidade> 
deve "[...] levar a um conhecimento das nossas sociedades atuais" para "[...] estabelecer uma relação até então incerta entre a cultura e as realidades econômicas e sociais" (Circular no IV 67-446, de 12 de outubro de 1967). Nos programas de 1982, a formulação é quase idêntica, mas talvez, para maior clareza, é adicionada a intenção “[...] de preparar cidadãos mais lúcidos e conscientes de suas responsabilidades” (BOEN, no 4, de 29 de abril de 1982). Em 1987, 1992, 1998, datas das mudanças dos programas e da publicação dos novos regulamentos, encontra-se quase exatamente a mesma formulação. Essa compreensão do mundo social supõe, insiste-se nisso nas primeiras instruções de 1967, construir "uma atitude intelectual" para "descrever e analisar" os fenômenos sociais. Mas isso não é tão simples porque dizem que o aluno "[...] é mais ou menos engajado, já possui um conjunto de noções confusas, preconceitos; ele está mais ou menos sujeito a 'mitologias'” (1967, p. 17). Quais serão as ferramentas, os métodos e os meios dessa compreensão? Qual será o conteúdo? Como levar em conta as experiências dos alunos, seus conhecimentos sobre os eventos atuais e ajudá-los a ter o recuo necessário para a análise? Pois, para os professores das CES, este é um dos objetivos essenciais: “[...] acho que este é o tipo de tema que pode desencadear, eu diria [...] um recuo com relação às coisas mais óbvias da vida. [...] [o aluno] pode questionar-se de forma a encontrar respostas interessantes. [Ele] pode evoluir... construir-se" (S.T., professor da CES, Paris, pesquisa INRP 1998).

Hoje, a resposta a essas perguntas é expressa na regulamentação em referência às áreas das disciplinas acadêmicas, sociologia e economia, principalmente. Desde 1988, menciona-se a necessidade de preparação dos alunos para futuros cursos universitários. Mas as coisas não são expressas desta forma nos textos anteriores de 1970 e 1982 - nunca se faz menção explícita de disciplinas, mas de campos de pesquisa e do ensino universitário na área das ciências sociais. Não se menciona de querer fazer desta matéria uma propedêutica para os estudos universitários. Assim, não se fala em ensinar sociologia, mas os termos estudos sociais ou análise social são utilizados. Para essa análise, são emprestados um vocabulário, conceitos, teorias subjacentes sempre abertos, em debate. Os tópicos dos estudos que se pode qualificar de sociais ou sociológicos quase não mudaram durante estes 30 anos. São eles: no primeiro ano, a família; no segundo ano (desde 1982), grupos sociais, cultura e sociedade, socialização; no último ano, mudança social (muito ampliada após 1994), assim como a dimensão sociológica das questões de vertente econômica, por exemplo: o consumo, no primeiro ano. Mas a forma de estudar essas questões, isto é, a forma de incentivar os alunos a pensar e, portanto, se livrar dos preconceitos, dos estereótipos, e a considerar esses fenômenos como fazendo parte de fatos sociais, evoluiu.

Com o mesmo objetivo, dois modelos de didatização se sucedem nos textos e se sucedem ou entram em concorrência na realidade do ensino de aspectos sociais ou sociológicos das CES.

104 Educação \& Realidade, Porto Alegre, v. 39, n. 1, p. 99-111, jan./mar. 2014 Disponível em: <http://www.ufrgs.br/edu_realidade> 


\section{Da Análise Social...}

O primeiro modelo, aquele dos anos 1970 e 1980, designamos como visando à análise social. Caracterizá-lo não é simples, porque por modelo didático entendemos algo como a representação simplificada do ensino real. Mas o conteúdo do ensino, o currículo real, não se deixa caracterizar apenas por programas ou instruções. Os livros didáticos, a formação de professores, os hábitos de uma disciplina, o estado de espírito dos alunos etc. também contribuem a delinear as suas principais características. A distância analítica a qual se quer ensinar aos estudantes é procurada durante esse primeiro período sem pretender fazer entrá-los em raciocínios sociológicos reais. O recuo ocorre por meio do desvio da história, da antropologia e com a preocupação recorrente de medir rigorosamente os fenômenos sociais, querendo tornar os alunos conscientes da relação entre eles, das cadeias de causalidades possíveis.

Os regulamentos são claros sobre a necessidade desse distanciamento. As instruções expressam-nos: "Deve se estabelecer certa relatividade dos fenômenos, se conscientizar das distâncias, das diferenças, e se houver das permanências" (Instruções de 1967). "Tem que insistir vigorosamente sobre a necessidade de levar em conta esta evolução histórica das economias e sociedades sobre um longo período de tempo [...] para medir o peso cujo passado ainda exerce sobre nós", martelam novamente as de 1982. Elas enfatizam a relatividade das classificações ou até dos mecanismos. Elas se referem à pluralidade das ciências da sociedade para abordar os problemas estudados. De fato, os programas são expressos primeiramente em termos de objetos ou problemas, e não em uma ou mais lógicas disciplinares. No entanto, se se consegue achar um todo coerente, ele irá evoluir: perspectiva histórica e de comparação internacional antes de 1982, perspectiva mais nitidamente inspirada na economia depois de 1982, em que a dinâmica das estruturas é estudada conforme uma inspiração humanista ou marxista. O programa, depois de 1982, discute a evolução das estruturas produtivas, os modos de organização, os padrões de consumo etc. As questões sociais são associadas às transformações econômicas e técnicas, as quais se constituem em contexto ou subproduto.

Em todos os casos, enfatiza-se a historicidade, a variedade contextual dos fenômenos sociais que levam os professores, auxiliados pelos livros didáticos, a organizar e enriquecer a reflexão dos alunos, baseando-se na história, na antropologia e nas estatísticas sociais, mais do que diretamente na sociologia.

Lendo o material didático, de fato, se vê de quais apoios podem dispor os professores. O livro do segundo ano, edição Hatier (Bremond et al., 1985), um dos dois mais comumente usados em sala de aula, por exemplo, oferece um dossiê intitulado Indivíduo e Sociedade. Os documentos apresentados são, em maioria, trechos de textos de caráter etnográfico (o relatório do Dr. Itard sobre Victor, trechos de Mauss, Clastres etc.) ou dados estatísticos do INSEE ${ }^{3}$. 
Entretanto os programas e os livros não comportam todo o ensino. Cada professor constrói um ensino coerente para si mesmo. Mas a formação sociológica da maioria dos professores era, naquele tempo, modesta. Cerca de $70 \%$ deles têm uma formação inicial em ciências econômicas, e $6 \%$ a $8 \%$ em sociologia. Além disso, se com o sistema IUFM ${ }^{4}$ a preparação aos concursos oferece agora uma sólida formação em sociologia (e ciências políticas), não era geralmente o caso para aqueles mais antigos que se tornaram professores na década de 1970 ou durante os anos 1980. Há razão para acreditar que a lógica econômica, na sua versão política, organizava fundamentalmente os seus discursos.

\section{Até a Sociologia...}

A referência explícita à sociologia, assim como à economia, aparece nos programas em 1988. Ela se define melhor naqueles de 19931994, ao mesmo tempo em que aumenta o peso dos itens sociológicos nos currículos e livros didáticos. A construção do programa do terceiro ano é completamente revista, como consequência da queda do Muro de Berlim. Como continuar estudando as transformações econômicas e sociais dos países socialistas em plena efervescência e desorganização social no Leste? A referência tanto aos sistemas quanto às estruturas desaparece dos programas.

No segundo ano (1994), por exemplo, não se fala mais em "estruturas, organizações, instituições sociais", mas em "quadros sociais da atividade econômica e social". A palavra quadro substitui estrutura no título da parte social ou sociológica do programa, sem discussão sobre a sua aparição. A coerência global do programa mais recente do segundo ano (2001) justifica-se a partir de uma questão verdadeiramente sociológica: "Como é possível a sociedade? Como a vida social não leva a uma guerra de todos contra todos? Se a sociedade produz a si mesma, quais são os mecanismos que garantem a coesão social?" Os capítulos da sociologia (estratificação, socialização, cultura, regulação e controle social) ocupam cerca de um terço do tempo de ensino recomendado.

A título de comparação, observe-se que no capítulo de um livro recente de segundo ano (Bordas, 1999) sobre o mesmo tema mencionado acima - Do indivíduo à sociedade-de 31 documentos mais da metade são trechos de sociólogos reconhecidos do passado ou contemporâneos. No modelo anterior, as referências eram as da história, da etnologia e de dados sociais. $\mathrm{O}$ atual modelo propõe uma abordagem para a mesma pergunta em termos de interdependências. Os autores e as obras sociológicas reconhecidas são mais fortemente mobilizados. Em ambos os casos, o objetivo didático é o mesmo: levar os alunos a observar com recuo as suas representações e suas experiências. Mas, como se pode ver, os meios para conseguir esse resultado são bastante diferentes.

106 Educação \& Realidade, Porto Alegre, v. 39, n. 1, p. 99-111, jan./mar. 2014 Disponível em: <http://www.ufrgs.br/edu_realidade> 


\section{O Lugar da Sociologia em Questão}

Uma análise dos programas, dos livros didáticos e dos assuntos

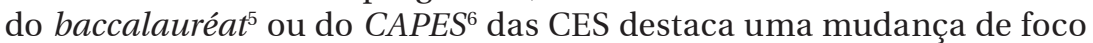
da análise social para a sociologia. Se mantivermos uma visão relativamente vertical da transposição, podemos caracterizar a evolução que descrevemos sobre as questões sociais como uma mudança de referência científica nos programas das CES, passando da legitimação multidisciplinar com referência à história, à antropologia e aos dados sociais, para a legitimação por referência à sociologia. No entanto esta interpretação não esgota a questão em debate, aquela sobre o espaço e os métodos de ensino reais das questões sociais na formação dos alunos. De fato, destacamos que, desde que foi estabelecido, o conteúdo do ensino é em grande parte determinado pela formação econômica predominante dos professores que o implementaram. Assumindo uma visão menos vertical, percebe-se em primeiro lugar que as mudanças relatadas foram acompanhadas de permanências; depois, que a dinâmica da mudança é complexa, principalmente por causa da influência dos problemas políticos e sociais do momento sobre o ensino nessa disciplina.

\section{Os Limites das Mudanças}

Se a leitura dos programas e livros didáticos permite delinear dois modelos de educação sucessivos, é bem possível que na realidade do ensino eles não se sucedam, mas coexistam.

Os tópicos do baccalauréat, por exemplo, testemunham a permanência de certas interrogações. Esse é o caso da questão da mobilidade social, frequentemente presente tanto em 1978 quanto em 1998. A questão científica não é a única causa. Outros bons motivos estão aqui envolvidos, de acordo com Nicole Pinet (1999): a questão social e política deste tema, o fato de que seja objeto de debates teóricos e que seu estudo possa facilmente se embasar em diversos documentos, também propiciando um trabalho metodológico. Há um interesse especificamente escolar no seu estudo. Outros tópicos resistem ao tempo e são encontrados durante todo o período: o papel da escola, a classe trabalhadora e seu declínio, o crescimento das classes médias.

Mais fundamentalmente, há uma forma característica de trabalho, o que pode ser chamado de "pedagogia das CES" (Chatel et al., 2001). Nas salas de aula, os professores definem o quadro geral da aula, mas eles costumam delegar a sua trama detalhada como forma de interação com os alunos, apoiados por um conjunto de documentos. Esses arquivos são apresentados nos livros didáticos. Este tipo de pedagogia consiste, numa perspectiva com conotação construtivista, a manter com firmeza a coerência global do curso, sem dizer tudo. Os elos faltantes são mais ou menos descobertos pelos alunos, numa interlocução entre eles e com o professor, com a ajuda dos documentos. Esse tipo

Educação \& Realidade, Porto Alegre, v. 39, n. 1, p. 99-111, jan./mar. 2014.

Disponível em: <http://www.ufrgs.br/edu_realidade> 
de trabalho é constante. Ele começa modestamente no primeiro ano, desenvolve-se plenamente no segundo ano e é considerado assimilado no terceiro ano, quando em geral é presente esporadicamente. Ele necessita de documentos que permitam alguns questionamentos, mas sem incerteza excessiva. As tabelas de mobilidade se mostram como boas ferramentas pedagógicas no terceiro ano, assim como os textos de autores no ensino de especialidade. Ambos necessitam claramente de um domínio real do seu conteúdo pelos professores.

A permanência deste trabalho é facilmente explicada: ele é um costume profissional reivindicado; em geral, ele é viável e coerente com os focos do baccalauréat das CES (a dissertação sustentada por um conjunto de documentos, a síntese dos documentos com perguntas preparatórias). Ele leva os alunos a se apropriarem de "esquemas de raciocínio" (Passeron, 2001) com base na sequência: observação, análise, interpretação, com a alternância de trabalhos orais e escritos.

\section{A Permeabilidade da Educação em Relação às Questões Políticas e Sociais}

De fato, a conjuntura social e política desempenha um papel no ensino das CES. O desaparecimento dos sistemas socialistas, por exemplo, requer uma revisão dos programas de terceiro ano, fazendo desaparecer a parte dedicada ao seu estudo, e leva a uma arquitetura do programa de 1994 completamente redesenhada. Da mesma forma, pode-se ver um vínculo entre a conjuntura da crise social ligada ao crescimento do desemprego, à pobreza, à exclusão e a extensão do tema sociológico no terceiro ano, em 1994, ou o tema da ligação social, no segundo ano. No entanto a trajetória que transforma os problemas políticos e sociais como objetos de ensino é complexa. Para que os problemas sociais se aninhem no currículo, eles precisam ser legitimados por sua entrada nos programas e também se revelarem ensináveis, ou seja, acessíveis a professores e seus alunos.

Sobre os aspectos sociais e sociológicos dos programas das CES, essas reformulações dos programas são às vezes realizadas por iniciativa de professores do Ensino Médio, às vezes, de especialistas universitários.

Por exemplo, a introdução dos termos sistemas e estruturas acontece no programa em 1982. Estas designações substituem aquelas de países socialistas, selecionadas pelos primeiros idealizadores dos programas, historiadores e geógrafos. Não é uma mudança na sociedade em geral que explica a reformulação dos programas, mas um elemento contextual interno à história das CES e do sistema de educação. Por ocasião de um conflito com a autoridade de supervisão, os professores mobilizam-se, com o apoio dos alunos e de suas famílias, para defender o seu ensino contra o que eles interpretam como um reducionismo econômico. Formado em economia na década de 1960, período em que

108 Educação \& Realidade, Porto Alegre, v. 39, n. 1, p. 99-111, jan./mar. 2014 Disponível em: <http://www.ufrgs.br/edu_realidade> 
um dos cursos de graduação intitulava-se Sistemas e Estruturas, eles abordam a economia como ciência social e se apoiam em economistas do INSEE, cujos trabalhos confortam essa perspectiva. Isso explica o consequente desenvolvimento no interesse pelas estatísticas sociais maciçamente presentes nos arquivos de documentos, que muitas vezes provêm das publicações do INSEE, e notadamente dados sociais. A mudança, que é realizada então por iniciativa de professores, passa facilmente, já que ela se alinha com seus conhecimentos iniciais e se encaixa com suas orientações ideológicas.

Com o desaparecimento nos programas das questões relacionadas às economias e às sociedades ex-socialistas, a situação é muito diferente. É a reforma pedagógica dos estabelecimentos de Ensino Médio que se implementa; comissões reuniram-se de forma extensa para preparar esses textos. A influência dos especialistas é aparente. Henri Mendras certamente desempenha um papel na reformulação da parte sociológica do programa de 1994, especialmente na introdução dos autores no ensino da especialidade. Isso é invocado em suas memórias (1995). Os professores estão envolvidos, mas o programa não se alinha sob um ponto de visto plenamente consensual entre eles. Pelo contrário, as reações dos professores são divididas. Alguns são muito críticos em relação a esse ensino de autores e qualificam o deslizamento que evocamos como uma tendência para o academicismo. Mas outros vão elogiar essa evolução para a qual eles tentam contribuir.

A conjuntura social na qual se encontram os professores e alunos tem um impacto direto sobre o ensino, de forma um pouco independente dos programas. Ela intervém por meio dos documentos utilizados no estudo, aqueles que estão disponíveis, sejam dados estatísticos ou livros disponibilizados para os professores para preparar suas aulas etc. Ela também provém de diversos meios de comunicação que fazem um problema se tornar familiar e, a partir disso, surge na sala de aula, nem que seja pela voz dos alunos. É o caso, por exemplo, da questão da integração. Esse termo é amplamente utilizado pelos estudantes do primeiro ano (pesquisa INRP ${ }^{7}$ 1998, Chatel et al., 2003), mesmo que ele não conste no programa. Ele aparece em seus textos como uma espécie de elemento central, uma palavra-chave que introduz explicações e também expressa preocupações. Ele permite expressar conhecimentos, experiências extraescolares, ajuda a se situar no espaço social.

\section{Conclusão}

Quando os professores das CES, em 1980, dizem que estão lutando "para o adjetivo social", eles contribuem em manter na escola o único ensino que pretende fazer a iniciação à sociologia. Mas nada garante que eles tiveram o projeto unânime de promover assim o ensino da sociologia. Depois disso, a junção de várias ciências sociais na CES torna-se mais claramente uma junção economia-sociologia para estu- 
dar algumas das principais questões econômicas e sociais do momento. Essa posição instala de forma duradoura a disciplina escolar em um território específico, protegendo-a da concorrência das disciplinas próximas, história e geografia, por um lado, e do outro a economia-direito em ciências e tecnologias terciárias, via técnica das escolas do Ensino Médio. Também apoiadas pela agregação, as ciências econômicas e sociais ganham maior visibilidade e uma certa força no sistema escolar, até porque, lembre-se, esse ensino desperta continuamente o interesse dos alunos. No entanto essa evolução não é unanimemente considerada positiva pelos professores das CES. Alguns veem a conexão aparente com a economia de um lado, e da sociologia do outro, como uma perda de identidade das CES, um fechamento no academicismo; enfatizam a tentação de desistir do que proporciona o significado profundo do seus ensinamentos, a educação para a cidadania crítica. Esse debate, interno à profissão, lembra que em questão do ensino das ciências da sociedade não se pode escapar à natureza política dos problemas a serem estudados. Isso envolve tanto as próprias modalidades do ensino quanto as escolhas curriculares debatidas publicamente.

Recebido em 06 de março de 2013 Aprovado em 03 de dezembro de 2013

\section{Notas}

1 N. T.: ES é a especialização do segundo grau, Économique et Sociale.

2 N. T.: Ciências Econômicas e Sociais (CES) é a tradução de Sciences Économiques et Sociales (SES).

3 N. T.: Institut National de Statistique Économique et Social (INSEE).

4 N. T.: Instituto Universitário de Formação de Professores (Maîtres-IUFM).

5 N. T.: Baccalauréat: diploma do fim do segundo grau, comparável ao Enem.

6 N. T.: O Certificat d'Aptitude au Professorat de l'Enseignement du Second degré (CAPES) é um diploma fornecido pelos IUFM, permitindo trabalhar como professor nos estabelecimentos do primeiro e segundo grau.

7 N. T.: Institut National de Recherche Pédagogique (INRP) é o Instituto Nacional de Pesquisa Pedagógica.

\section{Referências}

BRÉMOND, Janine et al. Manuel de Sciences Économiques et Sociales: classe de première. Paris: Hatier, 1989.

COHEN, Albert et al. Manuel de Sciences Économiques et Sociales: classe de première. Paris: Bordas, 1999.

CHATEL, Elisabeth et al. Élèves et Professeurs en Classe de Sciences Économiques et Sociales. Paris: INRP, 2001.

CHATEL Elisabeth et al. Apprendre la Sociologie au Lycée. Paris: INRP, 2003.

110 Educação \& Realidade, Porto Alegre, v. 39, n. 1, p. 99-111, jan./mar. 2014

Disponível em: <http://www.ufrgs.br/edu_realidade> 
CHATEL Elisabeth; GROSSE, Gérard; RICHET, Adeline. Professeur de Sciences Économiques et Sociales au Lycée, un Métier et un Art. Paris: CNDP-Hachette, 2002.

CHEVALLARD, Yves. La Transposition Didactique: du savoir savant au savoir enseigné. Grenoble: La Pensée Sauvage, 1985.

HAMELINE, Daniel. Rapport du Colloque sur L'enseignement des Sciences Économiques et Sociales. Rennes, 23 mar. 1998. Comité Meirieu, consultation "Quels savoirs enseigner dans les lycées?".

MENDRAS, Henri. Comment Devenir Sociologue, Souvenirs d'un Vieux Mandarin. Arles: Actes Sud, 1995.

PASSERON, Jean-Claude. Le Raisonnement Sociologique: la preuve et le contexte, Les Conférences de l'Université de tous les savoirs (UTLS 2000). In: MICHAUD, Yves (Org.). Qu'est-ce que la Société? Paris: Odile Jacob, 2001. p. 38-51.

PINET, Nicole. De la Sociologie aux Sciences Économiques et Sociales. DEES, n. 115, p. 16-18, mar. 1999.

VERRET, Michel. Le Temps des Études. Paris: Honoré Champion, 1974.

Elisabeth Chatel é professora de Ciências da Educação na Universidade de Rouen, França.

E-mail: elisabeth.chatel@gmail.com

Gérard Grosse é professor de Ciências Econômicas e Sociais do Liceu Racine, França.

E-mail: grosse.gerard2@wanadoo.fr

Tradução de Amurabi Pereira de Oliveira 